\title{
Preference for different relaxation techniques by COPD patients: comparison between six techniques
}

This article was published in the following Dove Press journal: International Journal of COPD

19 September 2016

Number of times this article has been viewed

Michael E Hyland,' David Clare Seamark, ${ }^{3}$ Margaret Pinnuck, ${ }^{3}$ David Ward, ${ }^{3}$ Ben Whalley, ${ }^{\prime}$ Colin J Greaves, ${ }^{4}$ Adam L Hawkins, ${ }^{5}$ Dave Seamark ${ }^{3}$

'School of Psychology, University of Plymouth, Plymouth, ${ }^{2}$ Department of Respiratory Medicine, Royal Devon and Exeter Hospital, Exeter, ${ }^{3}$ Honiton Group Practice, Honiton, ${ }^{4}$ University of Exeter Medical School, Exeter, ${ }^{5}$ GSK House, Brentford, UK

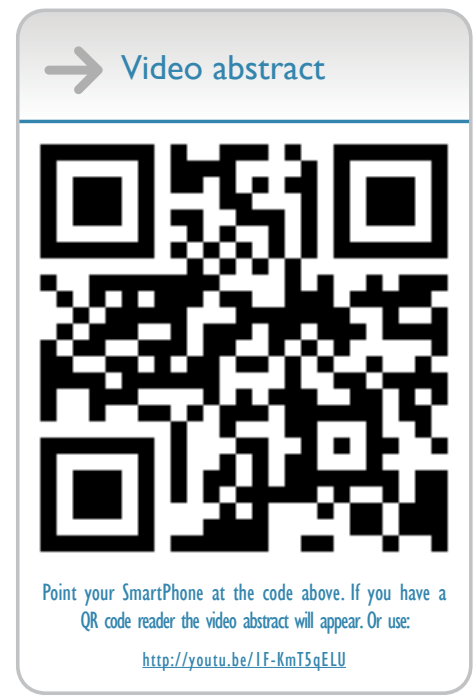

Correspondence: David MG Halpin Department of Respiratory Medicine, Royal Devon and Exeter Hospital, Exeter, Devon EX2 5DW, UK Email d.halpin@nhs.net MG Halpin, ${ }^{2}$ Sue Blake, ${ }^{3}$

Background: A review of the effectiveness of relaxation techniques for chronic obstructive pulmonary disease patients has shown inconsistent results, but studies have varied in terms of technique and outcome measures.

Aim: To determine patient preference for different relaxation techniques.

Methods: Chronic obstructive pulmonary disease patients were presented with six techniques via a DVD and asked to rate the techniques in terms of effectiveness, rank in order of likely use, and comment.

Results: Patients differed in the technique preferred and reason for that preference, but the most commonly preferred technique both for effectiveness and ease of use was "thinking of a nice place" followed by progressive relaxation and counting. Familiarity and ease of activity were commonly given reasons for preference.

Conclusion: Rather than providing patients with a single technique that they might find difficult to implement, these results suggest that it would be better to give a choice. "Thinking of a nice place" is a popular but under-investigated technique.

Keywords: COPD exacerbation, anxiety, relaxation techniques

\section{Introduction}

People with chronic obstructive pulmonary disease (COPD) experience episodes of breathlessness, both as a feature of their stable disease and at the time of exacerbations, which could be life threatening if associated with severe respiratory failure. Not surprisingly, these episodes are very frightening for patients. Anxiety is a common comorbidity in COPD patients, and it can increase symptom perception. Panic and fear are emotions frequently described by patients prior to admission to hospital with an exacerbation of COPD. ${ }^{1}$ Patients high in anxiety are more likely to respond with fear to symptoms of breathlessness. Fear induces a stress response, which may further worsen the sensation of breathlessness and trigger a call for emergency assistance. Reducing patient's anxiety could lead to a reduction in the overall burden of symptoms in COPD patients, better coping with exacerbations, fewer calls to emergency services, and decreased hospitalizations.

All relaxation techniques have some form of mental focus, such as tai chi, qi gong, and yoga, where there is mental focus on body movement or posture. Mindfulness is the term given to a group of techniques where the person is mindful of the present. Mindfulness can include focusing on breathing, but also focusing on emotional states. Mantra techniques (eg, transcendental meditation) involve repeating a word or sequence of words, where the words may or may not have meaning. Guided imagery 
techniques include those where the person focuses on some positive form of experience. Mental focus is believed to have a number of benefits, including preventing patients from ruminating on negative cognitions.

Regular practice of relaxation techniques has been shown to reduce trait anxiety levels and stress, ${ }^{2,3}$ and the use of relaxation during a period of increased breathlessness could help patients reduce state anxiety and fear when breathlessness increases. Some studies provide evidence of positive outcomes with different relaxation techniques, for example, with a taped message, ${ }^{4}$ guided imagery, ${ }^{5}$ progressive muscle relaxation, ${ }^{6}$ music, ${ }^{7}$ and mindfulness. . $^{8,9}$

However, not all relaxation techniques are effective, ${ }^{10}$ and the conclusion from a recent review ${ }^{11}$ is that there is uncertainty about the benefit of relaxation for COPD due to the variability of results, variability of techniques used, and variability of outcome measures.

It is generally recommended that techniques for relaxation should be individualized to patients, as patients have different preferences. ${ }^{12}$ Patients are more likely to adhere to and practice preferred techniques compared to nonpreferred techniques.

In this study, we have used a mixed methods approach to explore the preferences of patients with COPD for different relaxation techniques, with a view to identifying those most suitable for use as a self-help intervention in clinical practice.

\section{Methods}

\section{Relaxation techniques}

The six techniques used in this study were selected so as to represent variety of commonly used types of relaxation. All involve some kind of mental focus, which is the common feature of all relaxation techniques. One commonly used mindfulness technique is to focus on breathing. However, as breathlessness is a symptom of COPD, focusing on breathing has the potential to increase negative cognitions this technique was not used.

\section{Counting}

Patients were instructed to count from 1-5 over and over again in their head.

\section{Word repetition}

Patients were instructed to repeat a meaningless word, which they used only for relaxation so that the word would become associated with relaxation.

\section{Body relaxation}

Patients were given a series of instructions consistent with progressive relaxation (progressive muscle relaxation).

\section{Positive imagery}

Patients were instructed to generate a positive emotion by imagining a ball of light filling them with rays of happiness and love.

\section{Nice place}

Patients were instructed to imagine a nice place where they feel happy and relaxed and then focus on the experience of being in that nice place. This is a version of guided imagery.

\section{Body movement}

Patients were instructed in a simple form of Kundalini yoga - focusing on lifting and lowering the hand slowly.

Short video clips explaining each of these techniques and instructing patients how to perform them were made.

\section{Procedure}

The study was conducted over a 3-month period in 2014. We aimed to recruit 20 subjects from hospital inpatients who had recently been admitted with an exacerbation of COPD. The interview process was explained and if they agreed to participate written informed consent was obtained. The study received ethical approval from NRES Committee West Midlands-Coventry and Warwickshire (ref 13/WM/0269).

The video clips of the six forms of relaxation were shown to patients on a laptop at their bedside on the respiratory ward. In order to reduce order effects (ie, increased preference for an earlier or later presentation), the six forms of relaxation were presented in three different orders, two of which were reversed. Patients were asked to try to undertake each type of relaxation technique once. A short gap of approximately 1 minute was left between each technique. If patients said they did not feel comfortable trying them out there and then, they were asked if they felt they would be able to practice them at home as the study was designed to assess patients' views on whether or not they felt they would be able to use the technique at home. They were not coached in the techniques by the interviewer.

Patients were asked to rate each technique immediately after it was shown. They were asked to score the effectiveness of each technique by rating their relaxation on a scale of $1-10$, where 10 was very effective. They could give the same score to more than one technique if they wished. 
Patients were asked to explain how they felt about each presentation. After seeing all the techniques, patients were asked to rank all the six techniques in order of preference in terms of whether or not they thought they could perform the technique at home or elsewhere. Patients' comments during the interview were transcribed and analyzed initially by Sue Blake with confirmation by Dave Seamark, with comments allocated into two groups, positive and negative for each technique.

\section{Results}

Twenty-four patients were asked if they were willing to participate in order to reach the enrolment target of 20 . The demographics of the 20 patients included in the study are shown in Table 1. The mean age of the patients was 67 years (range 47-84 years). They were all Caucasians; 13 (65\%) were women and all had left school at or before the age of 16 years. All had smoked with a range of pack-years from 18 to 94 .

\section{Quantitative}

Table 2 shows the mean scores for the effectiveness of each of the techniques, the number of times each technique was ranked either first (most likely to be performed at home or elsewhere), second, or third, as well as standard deviations and maximum and minimum ratings. The measures of dispersion show the considerable variation in preference between the six techniques, and all but two techniques were ranked

Table I Demographics of the patients included in the study

\begin{tabular}{llllll}
\hline No & $\begin{array}{l}\text { Age } \\
\text { (years) }\end{array}$ & $\begin{array}{l}\text { Sex } \\
\text { school (years) }\end{array}$ & $\begin{array}{l}\text { Age at leaving } \\
\text { schoking history }\end{array}$ & $\begin{array}{l}\text { Carers at } \\
\text { home }\end{array}$ \\
\hline I & 64 & F & I4 & 18 & Two sons \\
2 & 68 & M & 15 & 25 & Lives alone \\
3 & 74 & M & 14 & 60 & Spouse \\
4 & 62 & F & 15 & 20 & Lives alone \\
5 & 47 & M & 16 & 31 & Partner/son \\
6 & 70 & M & 16 & 40 & Son \\
7 & 51 & F & 16 & 19 & Partner \\
8 & 63 & F & 15 & 50 & Spouse \\
9 & 79 & M & 14 & 94 & Spouse \\
10 & 77 & F & 15 & 31 & Spouse \\
II & 70 & M & 15 & 55 & Lives alone \\
I2 & 72 & F & 15 & 22 & Spouse \\
I3 & 65 & F & 15 & 30 & Spouse \\
I4 & 63 & F & 14 & 35 & Partner \\
I5 & 65 & F & 15 & 30 & Lives alone \\
16 & 69 & F & 16 & 25 & Lives alone \\
I7 & 62 & M & 16 & 29 & Partner \\
18 & 70 & F & 15 & 32 & Lives alone \\
19 & 65 & F & 15 & 40 & Spouse \\
20 & 84 & F & 16 & 40 & Lives alone \\
\hline
\end{tabular}

Abbreviations: $F$, female; $M$, male. first by at least one person. Thinking of a nice place was rated most effective and was ranked as the technique most likely to be performed by the majority of patients. Body relaxation and counting were ranked first by three and four patients, respectively, and were in second and third place in terms of effectiveness ratings. Other techniques received lower ratings and rankings.

There was some correlation between effectiveness ratings: if a person gave a high rating to counting, he/she also gave a high rating to word repetition $(r=0.5, P=0.025)$, and a high rating for positive imagery $(r=0.48, P=0.033)$.

\section{Qualitative}

A commonly given explanation for preferring "thinking of a nice place" was that it was easy to tap into positive memories, with patients giving examples in particular of country or seaside scenes:

"Yeah. I give that one a 10 (out of 10). I've done that. Thought nice things. It does bring you back quicker. Same as breathing really. Brings you back that much quicker.”

[Patient 14]

09: That was really good; I was on Sandy Bay beach with my wife and children.

Some patients substituted repeating a nonsense word by repeating a positive and familiar word, again showing the importance of prior experience.

14: Best one my daughter taught me was to repeat to myself "resume to normal, resume to normal, resume to normal".

By contrast, the novelty of instruction to generate a positive emotion created problems for some patients.

16: I can't do that one at the moment $[\ldots]$ because I know my family are not happy with me.

A common reason given for a positive evaluation of counting was that it was easy to do, with some patients perceiving it as a "more private" technique.

02: I found it very relaxing actually, I did, you're not thinking about breathing, you're thinking about the speed you're counting at, which takes you, I think if you are having an exacerbation it takes your mind away from it.

Body relaxation was perceived as using very little energy and associated with sleep.

05: I'll fall asleep listening to this one, very relaxing [...], because it doesn't involve any moving at all. 
Table 2 Number of times each technique was ranked first, second, or third for ease of use at home and mean rating of effectiveness $(\mathrm{N}=20)$

\begin{tabular}{|c|c|c|c|c|c|c|c|}
\hline \multirow[t]{2}{*}{ Technique } & \multicolumn{3}{|c|}{ Rankings } & \multicolumn{4}{|c|}{ Ratings $(1-10)$} \\
\hline & First & Second & Third & Mean & SD & Minimum & Maximum \\
\hline Nice place & 12 & 5 & I & 7.70 & 2.08 & 2 & 9 \\
\hline Body relaxation & 3 & 4 & I & 6.25 & 2.15 & 2 & 9 \\
\hline Counting & 4 & 2 & 3 & 6.05 & 2.44 & 2 & 10 \\
\hline Word repetition & I & 4 & 4 & 5.45 & 2.14 & 2 & 10 \\
\hline Positive imagery & 0 & 3 & 5 & 5.05 & 2.14 & 2 & 9 \\
\hline Body movement & 0 & 2 & 6 & 4.95 & 2.19 & I & 9 \\
\hline
\end{tabular}

Abbreviation: SD, standard deviation.

Negative comments, in particular with regard to body movement, but also to other techniques, tended to relate to the difficulty of doing the technique, or the effort required for its completion.

05: to be honest I'd say that was non-applicable to me, the sort of breathing fits I have, as I said to you, I'm rigid, I can't move my arm up and down, I just freeze on the spot as I am, just the lungs takes over.

A number of patients were already employing relaxation techniques at home.

17: I already do that one [...] I like that one, I do that one anyway. It's all relative to the person isn't it you know. It's just that I know it works for me (Nice place).

06: Once again I've done this. (Body relaxation)

SB: And does it help?

06: Oh yes, once you get into that relaxed feeling, you know you're not using any oxygen, it seems like the oxygen is going the other way really.

Other patients could envisage using the techniques with the proviso of a fall back plan if they failed to be effective.

SB: Could you see yourself doing that do you think? (Counting)

02: I think I could, yeah, I think I could. Especially if you're sat there on your own, I might be sat there doing it with a phone in my hand just in case, but [...]. At least then I could say well I tried counting and that didn't work, do you know what I mean?

\section{Discussion}

Patients varied in the perceived effectiveness preference for the different relaxation techniques and whether or not they would be able to practice them at home. Despite individual differences, the majority of patients felt that the technique of "thinking of a nice place" was both most effective and most likely to be practiced at home, with 12 out of 20 patients ranking it as most likely to be practiced at home. These findings are similar with those of a small study of preference amongst stroke patients ${ }^{13}$ where there was also a majority preference for "thinking of a nice place" as a technique for relaxation. However, in the study of stroke patients, second and third preferences were different from the effectiveness ratings and ease of use rankings reported here.

The reason that "thinking of a nice place" was perceived as the most effective and easiest to use at home cannot be determined from this study. We did not ask patients why they considered particular techniques easier than others but the results are consistent with findings that adding positive content to relaxation techniques is helpful. ${ }^{14}$ The qualitative data suggest that familiarity is an important component, and the ability to access the memory of previous relaxing and positive states mood states is helpful. "Counting" had a high mean rating and was ranked as the easiest to use by four out of 20 patients. Counting is also a familiar activity, but the qualitative data that report it to be a "private" activity suggest that for some patients being isolated from social aspects of life may be important for relaxation. Progressive relaxation also had a high mean effectiveness rating and was ranked as the most likely to be used by three out of 20 patients. The comments in relation to this and the "body movement" technique suggest that minimizing the use of oxygen can be perceived as important in this patient group and may explain differences compared to stroke patients. ${ }^{13}$

Individualization of the type of technique has been recommended because relaxation techniques are successful only if they are practiced. ${ }^{12}$ Uptake and adherence to mindfulness have been reported as poor for respiratory patients. ${ }^{11}$ Clinicians should consider that rather than trying to teach patients the techniques that they might find difficult, it would be better to give patients a choice of techniques. Relaxation techniques are already familiar to some patients. Familiarity of experience, ease of implementation, and positivity are all factors that can be important to patients and are likely to 
increase the chance that patients would use the technique at the time they become breathless.

Helping patients to cope with worsening periods of breathlessness by reducing anxiety using one of these techniques is a simple intervention. Patients thought they would be able to practice their preferred technique and use it at the time of an exacerbation, and some described using similar strategies in the past. Patients could be shown these techniques and encouraged to practice them in a number of situations: at a regular review, as part of pulmonary rehabilitation, or prior to discharge from hospital after an exacerbation. Once patients were shown the techniques, their ability to recall them and whether or not they had practiced or used them could be checked at subsequent clinic visits. Supporting materials, both printed and audiovisual, and involving their relatives or carers may also be useful to help patients remember how to practice the techniques.

Whether patients can remember the strategy and use it at the time of an exacerbation and what impact this might have on preventing admission to hospital should now be assessed in a prospective clinical trial.

\section{Acknowledgment}

The study received support from the small grants scheme of Royal Devon \& Exeter NHS Foundation Trust.

\section{Author contributions}

Dave Seamark was the guarantor of the study. David MG Halpin proposed the research questions and recruited the patients. Sue Blake carried out the interviews and together with Dave Seamark carried out the thematic analysis. Michael E Hyland and Ben Whalley produced the videos. All the authors contributed to the development of the interview schedule, took part in discussion at the design stage of the study, contributed to the interpretation of results, and contributed to writing the paper. Although Adam L Hawkins is employed by GSK, his involvement in the East Devon Respiratory Research Group is entirely in a personal capacity.

\section{Disclosure}

The authors report no conflicts of interest in this work.

\section{References}

1. Halpin D, Hyland M, Blake S, et al. Understanding fear and anxiety in patients at the time of an exacerbation of chronic obstructive pulmonary disease: a qualitative study. JRSM Open. 2015;6(12): 2054270415614543.

2. Hanley J, Stirling P, Brown C. Randomised controlled trial of therapeutic massage in the management of stress. Br J Gen Pract. 2003;53(486): $20-25$.

3. Herbert B, Klipper MZ. The Relaxation Response. New York: William Morrow and Company, Inc.; 2000.

4. Gift AG, Moore T, Soeken K. Relaxation to reduce dyspnea and anxiety in COPD patients. Nurs Res. 1992;41(4):242-246.

5. Louie SW. The effects of guided imagery relaxation in people with COPD. Occup Ther Int. 2004;11(3):145-159.

6. Renfroe KL. Effect of progressive relaxation on dyspnea and state anxiety in patients with chronic obstructive pulmonary disease. Heart Lung. 1988;17(4):408-413.

7. Singh VP, Rao V, Prem V, Sahoo RC, Keshav KP. Comparison of the effectiveness of music and progressive muscle relaxation for anxiety in COPD-a randomized controlled pilot study. Chron Respir Dis. 2009; 6(4):209-216.

8. Benzo R. Mindfulness based stress reduction in severe COPD: pilot on feasibility, effect on quality of life and qualitative analysis. Am J Respir Crit Care Med. 2011;183.

9. Chan RR, Giardino N, Larson JL. A pilot study: mindfulness meditation intervention in COPD. Int J Chron Obstruct Pulmon Dis. 2015; $10: 445-454$

10. Mularski RA, Munjas BA, Lorenz KA, et al. Randomized controlled trial of mindfulness-based therapy for dyspnea in chronic obstructive lung disease. J Altern Complement Med. 2009;15(10):1083-1090.

11. Harrison SL, Lee A, Janaudis-Ferreira T, Goldstein RS, Brooks D. Mindfulness in people with a respiratory diagnosis: a systematic review. Patient Educ Couns. 2016;99(3):348-355.

12. Spence JD, Barnett PA, Linden W, Ramsden V, Taenzer P. Lifestyle modifications to prevent and control hypertension. 7. Recommendations on stress management. Canadian Hypertension Society, Canadian Coalition for High Blood Pressure Prevention and Control, Laboratory Centre for Disease Control at Health Canada, Heart and Stroke Foundation of Canada. CMAJ. 1999;160(9 Suppl):S46-S50.

13. Wang SX, Hyland ME, Sutcliffe K, Christensen A. Relaxation techniques for stroke survivors: findings from a patient and public involvement project in the UK. Int J Stroke. 2015;10:182-183.

14. Gaitan-Sierra C, Hyland ME. Mood enhancement in health-promoting non-aerobic exercise: the role of non-specific mechanisms. $J$ Health Psychol. 2014;19(7):918-930.
International Journal of COPD

\section{Publish your work in this journal}

The International Journal of COPD is an international, peer-reviewed journal of therapeutics and pharmacology focusing on concise rapid reporting of clinical studies and reviews in COPD. Special focus is given to the pathophysiological processes underlying the disease, intervention programs, patient focused education, and self management protocols

\section{Dovepress}

This journal is indexed on PubMed Central, MedLine and CAS. The manuscript management system is completely online and includes a very quick and fair peer-review system, which is all easy to use. Visit http://www.dovepress.com/testimonials.php to read real quotes from published authors. 